\title{
A (in)sustentabilidade da imagem ${ }^{1}$
}

\author{
Leandro Belinaso Guimarães
}

... não há modo de "pensar de outro modo" que não seja, também, "ler de outro modo" e "escrever de outro modo",

Jorge Larrosa.

\section{À Amsterdã, pelo silêncio!}

que faz uma fotografia sobre o ambiente endurecer? Uma dureza quase impenetrável, quase sem interstícios, quase sem porosidades areníticas, quase sem fissuras! Uma imagem (aqui: a capa de um Caderno de jornal impresso) que já carrega em si mesma toda uma pastosa argamassa. Sua fotografia parece enrijecida sobre uma imensa palavra-tijolo que lhe serve de amparo: insustentável! De tão pesada, a foto parece afundada, imóvel, cinza

1 Este ensaio foi inteiramente escrito no tempo do pós-doutoramento que fiz junto ao "Centro de Estudos e Documentação Latino-americano" (CEDLA), em Amsterdã, nos Países Baixos, no primeiro semestre de 2013. O projeto que desenvolvi estava focado em escrever ensaios com imagens jornalísticas relativas à sustentabilidade, pensando em modos diferentes de fazê-las funcionar nos trabalhos que desenvolvo com a formação de professores no Brasil. Agradeço ao CEDLA por toda a estrutura oferecida que me permitiu conforto, ótimas bibliotecas, espaço e tempo para meus estudos. Também agradeço ao professor Fábio de Castro, pela acolhida ao meu projeto e, sobretudo, pelas instigantes perguntas sobre meus escritos. À CAPES, cujo auxílio me permitiu viver momentos formativos ímpares. À Universidade Federal de Santa Catarina pela concessão do afastamento, que espero retribuir através da intensificação dos projetos de pesquisa, ensino e extensão que me enredo. Dedico o ensaio aos amigos de CEDLA (Leopoldo e Shaji) e, especialmente, à pesquisadora Aleksandra Pudliszak com quem compartilhei um charmoso escritório no sótão da casa que abrigou o Centro durante minha visita. 
como cimento, na folha de jornal que a suporta. A palavra-legenda sob ela a captura, a toma, a sintetiza, a inibe. Vejamos, de partida, a imagem: a fotografia, as palavras, os vazios. E, ainda, o contexto jornalístico de sua exibição:
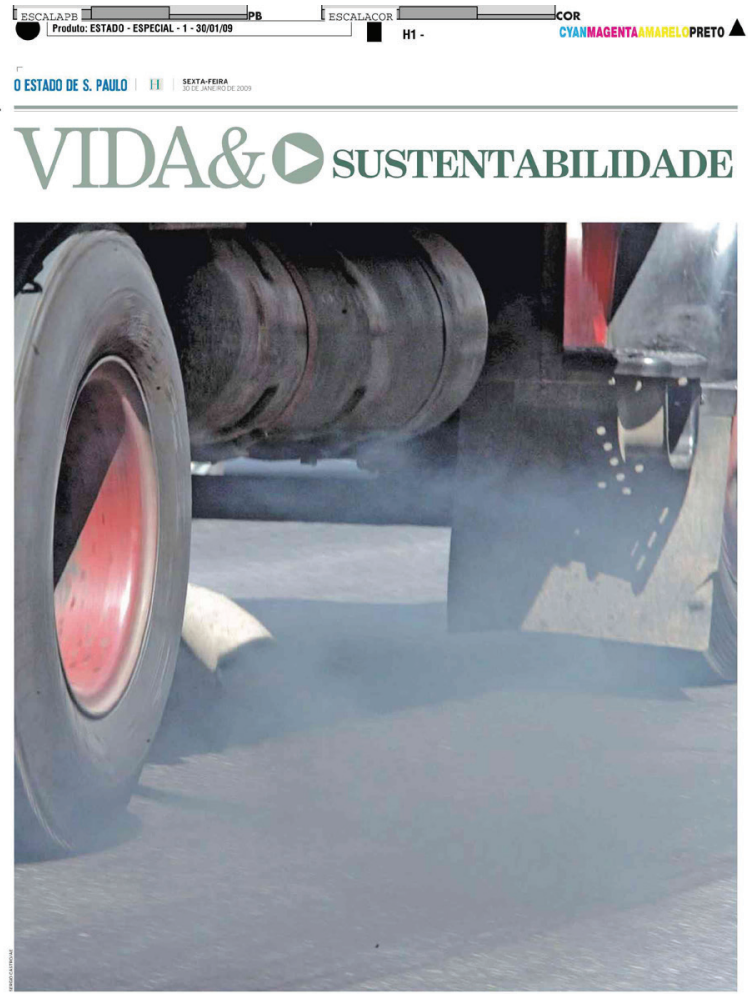

\section{Insustentável}

Oacordo que adiou a entrada em vigor de uma nova fase do programa de reduçăo das emissôes de poluentes por veículos pode resultar em mais 11 mil mortes por ano em 6 capitais brasileiras (pág. 4). Uma situaçâo como esta, de flagrante agressão ao meio ambiente, é exatamente o que sociedade e empresas tentam reverter. Mais do que modismo, a sustentabilidace traduz um compromisso com práticas que assegurema preservaçáo dos recursos hoje disponiveis para as geraçoes futuras. É o respeito a esse conceito que orientará a abordagem da nova série de cadernos especiais do 'Estado'

\section{As perspectivas} ambientais no início da era Obama mais responsáve o Ṕ́G. H5
Reflorestamento: técnica e pesquisa a serviço da proteção 
Estranho, ao mesmo tempo comum, cimento feito da fotografia. Ela funciona para unir e emparedar dois tijolos de palavras. No topo, "vida \& sustentabilidade" anunciam, afirmativamente, o título do "novo" Caderno jornalístico mensal (publicado ao longo do ano de 2009) do jornal "O Estado de São Paulo". Embaixo, na função de uma legenda-titulo, a enorme palavra insustentável (fortemente acentuada na imagem) sintetiza, solidifica, magnetiza o sentido maior da imagem-muro. Ali, presa entre uma afirmação (seu teto) e uma negação (seu chão), situa-se a fotografia.

E se retirarmos de cena as palavras e o contexto do Caderno jornalístico? E se ficarmos apenas com a fotografia? Ela perderia seu peso? Flutuaria, nos abrindo sentidos outros? Difícil vida demasiadamente emparedada da fotografia. Enclausurada nas tramas do "dispositivo da sustentabilidade" (GUIMARÃES, 2012), ela parece fadada a não ter, paradoxalmente, vida (vocábulo-título do "novo" Caderno), para além das palavras que a empacotam. Mesmo as retirando de cena, o super-close no escapamento de um caminhão (em sua porção final, pequena, mas ruidosa, imensa) mostra, em primeiro plano, o resultado enevoado do trabalho do elemento da maquinaria automobilística responsável pela eliminação dos resíduos da combustão. Tal acentuação focal o inscreve no mundo como um sujeito-objeto ativo e pouco intimidado pela imensa e bruta roda que gira ao seu lado. O sutil e ao mesmo tempo agressivo escapamento mostra sua força ao pintar com sua

2 "Todo dispositivo tem a função principal de responder a uma urgência e, por isso, possui um papel estratégico crucial na produção das verdades que predominam em determinados tempos históricos" (SAMPAIO e GUIMARÃES, 2012, p. 398). Um dispositivo é basicamente constituído por "[...] estratégias de relações de força sustentando tipos de saber e sendo sustentadas por eles" (FOUCAULT, 2003, p. 246 - grifos meus). 
presença esfumaçada o tom pálido, cinza, da fotografia. Ela nos convida à tosse, ao incômodo, à paralisia. Talvez, seguiríamos dizendo consensualmente (ao menos alguns, muitos dos que trabalham com educação ambiental) em silêncio, ou aos berros, ao olharmos apenas a fotografia da imagem: isto é insustentável!

Entretanto, quando olhamos a capa do Caderno, a que estaríamos efetivamente nos referindo com esta exclamação? Simplesmente a um presumível e falecido (embora exaustivamente circulante) significado que saltaria da imagem? Preferiria, não! Contudo, poderíamos responder: sim! É insustentável aquilo que a fotografia nos mostra, nos aponta, nos indica, nos ensina. Eis, aqui, um significado-clichê da imagem-capa! Sua montagem parece destinada à sua proliferação, uma vez mais. Ela abriga uma reconhecível e "naturalizada" foto sobre a poluição ambiental. Estivemos acostumados (ao menos desde os movimentos contestatórios ecologistas dos anos 1960 e 1970), quando se tratava de mostrar didaticamente a poluição, a ver fumaça saindo de fábricas (algo ainda visível na cultura do tempo presente). Mais recentemente, contudo, o foco nos automóveis parece se acentuar e substituir o cenário das distantes, agonizantes e, cada vez mais, cotidianamente "invisíveis" fábricas. Talvez, esta escolha pelo super-close no escapamento de um caminhão (que poderia ser em um automóvel de passeio) se configure para que a fotografia nos afete mais taxativamente. Possa, inclusive, "falar" dos nossos comportamentos, dos

3 Faço aqui uma alusão ao desconsertante livro escrito por Herman Mellville (2005) nos fins do século XIX, intitulado "Bartleby, o escrivão: uma história de Wall Street" (título conferido à obra em língua portuguesa através do primoroso trabalho editorial da Cosac Naify). Nele, seu personagem principal responde a todos os pedidos de seu chefe com a frase: "acho melhor não" ou "preferiria, não" (na tradução de Cássia Zanon para a Editora L\&PM), se recusando a fazer toda e qualquer tarefa a ele designada. 
nossos desejos de consumo, dos nossos modos insustentáveis de viver (diz, literalmente, a capa inaugural do Caderno jornalístico). Nas tramas do "dispositivo da sustentabilidade" fotos da poluição ambiental assumem outras penetrabilidades, procurando nos enlear de modo mais incisivo e subjetivo a elas.

Porém, na imagem de capa do Caderno jornalístico (na conjunção de palavras, vazios, fotografia) nossa exclamação poderia assumir outro nuance. Nossa indignação seria com o teto e o chão de palavras que estão sustentando a fotografia (que atuam, quem sabe, mesmo se não estivessem grafadas na imagem), a emoldurando, a aprisionando. Preferiria, não (e evitaríamos, assim, um pouco pelo menos, o esforço do pensamento)! Entretanto, incomodados, talvez disséssemos: sim! É tudo aquilo que sustenta a fotografia na imagem (sua sustentabilidade) que a enclausura em um quase homogêneo sentido. Seria para destinar a ela uma condição de flutuação, de vida, de disparadora de sentidos outros, que desejaríamos vê-la insustentável!

\section{caráter escolar da imagem}

A imagem parece exigir ser reconhecida sem equívocos, sem hesitações, como se fosse tecida tal como um desenho esquemático, escolar, ofertado aos alunos para que compreendam, absorvam, quase sem o exercício criativo do pensamento, de modo claro, límpido, transparente, a mensagem que está sendo ensinada. Há - e aqui escrevo inspirado no belíssimo texto de Michel Foucault (1988) sobre as pinturas de René de Magritte ${ }^{4}$ - certa produção,

4 Tive a oportunidade de visitar o Museu Magritte em Bruxelas, na Bélgica, no tempo do meu pós-doutorado no CEDLA. Li atentamente o livro de Michel Foucault como inspiração para as lentes que acionaria ao estar diante das 
na composição da imagem, de uma certeza inapelável. É o modo de disposição da fotografia e das palavras, que a escolarizam e a fazem anunciar, didaticamente, qual é a narrativa jornalística que leremos ao folhearmos o Caderno, cuja série se inaugurou com a capa em destaque neste ensaio. Uma operação feita através de uma espécie de dedo indicador geral que "aponta, mostra, fixa, assinala, impõe um sistema de reenvios, tenta estabilizar um espaço único”. (FOUCAULT, 1988, p. 35)

Talvez possamos exercitar a lente que nos propõe Foucault. Diz o filósofo que não temos o hábito de prestar atenção, em uma página de livro ilustrado, a esse pequeno espaço em branco, que serve de fronteira comum entre o desenho (no nosso caso, a fotografia) e as palavras. Conversando com as pinturas de Magritte, Foucault (1988) argumenta ser ali na pequena faixa incolor, neutra, vazia, que um apagamento do lugar-comum se processa. Quiçá ali, nos interstícios brancos da imagem, a voz escolar se embrulhe, se engasgue e o dedo indicador, confuso, deixe de permanecer estendido. Ali, entre a fotografia e as palavras algo se passa, outras relações se criam, se proliferam.

Em Magritte, ainda seguindo Foucault (1988), o enunciado contesta a identidade manifesta da figura. "O que parece exatamente com um ovo, se chama acácia; com um sapato, a lua; com um chapéu coco, a neve; com uma vela, o teto" (p.43). É interessante a operação de desconserto no escolar da imagem. Algo, a partir de um trabalho de dissociação, pode se passar entre a figura e a palavra. Tal exercício anularia a semelhança intrínseca, fixa,

telas. A visita à Bruxelas, ao museu e ao livro (e também aos impactantes quadros de Magritte hospedados no Museu "Boijmans van Beuningen”, em Rotterdã, nos Países Baixos) acabaram funcionando como ativadores dos argumentos tecidos neste ensaio. 
criada, por exemplo, na imagem de capa do Caderno jornalístico, entre a fotografia do escapamento e sua mais provável legenda-título: insustentável. Para perder algo do caráter escolar da imagem, precisaríamos - entre outras (im)possibilidades que comentarei na próxima seção - operar proximamente à Magritte. Assim, atentos ao branco, ao vazio, da borda comum entre a fotografia e a palavra escreveríamos logo abaixo da primeira: a neve ou $o$ teto ou $a$ lua ou...! E rabiscaríamos, até ver sumir (sem poder desaparecer com suas cicatrizes), a palavra-tijolo ao pé da emparedada foto, deixando-a flutuar apenas sob seu teto, incitando-nos a pensar sem muita sustentação. Criaríamos, quem sabe, nessa operação, uma imagem, de saída, (im)pensável e, quiçá, insustentável!

\section{Traços outros (de)compondo a imagem}

O super-close na fotografia da imagem que estamos decompondo parece também ter sido usado para que pudéssemos ver mais, para enxergarmos "bem" de perto. Próximos, em certa e "boa" medida, sentimos o insustentável calor infernal produzido pelo desmesurado e, ao mesmo tempo, minúsculo escapamento. O super-close está ajustado para que o caráter escolar da imagem se acentue, se efetive, se configure. Entretanto, e se produzíssemos tal fotografia a partir de um descomedido "super" foco que nos fizesse ver um pouco menos? É interessante pensar que o super-close usado para nos fazer ver "bem" de perto, passaria agora (se acentuadamente "super") a nos fazer ver "mais longe", ver menos e, ao mesmo tempo, mais. E isso seria possível se tal proximidade focal fizesse sumir o caminhão-contexto da fotografia, fazendo dele uma vertigem de luzes e cores. 
Seguiremos, aqui, com esse outro exercício de dissociação entre a foto e a palavra. Se na seção anterior atuamos na legenda-título da imagem, agora nosso esforço será desconsertar sua fotografia. Para isso, convocamos a arte de rua de Slinkachu ${ }^{5}$ (2008) e seu projeto chamado "Little people in the city". Vejamos, antes de continuar, a série "Last kiss" composta por duas imagens:

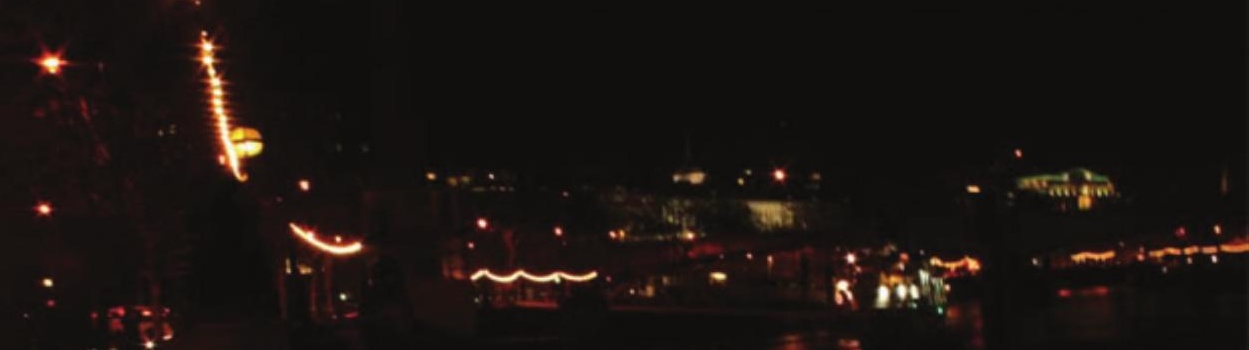

5 Conheci e comprei o livro na deslumbrante livraria "Selexyz Dominicanen", em Maastrich, sul dos Países Baixos. Situada no interior de uma antiga igreja, a livraria é tida como uma das mais bonitas da Europa. Visitei a cidade especialmente para conhecê-la e voltei de lá com a obra que me ajudou a tecer os argumentos da presente seção do ensaio. 


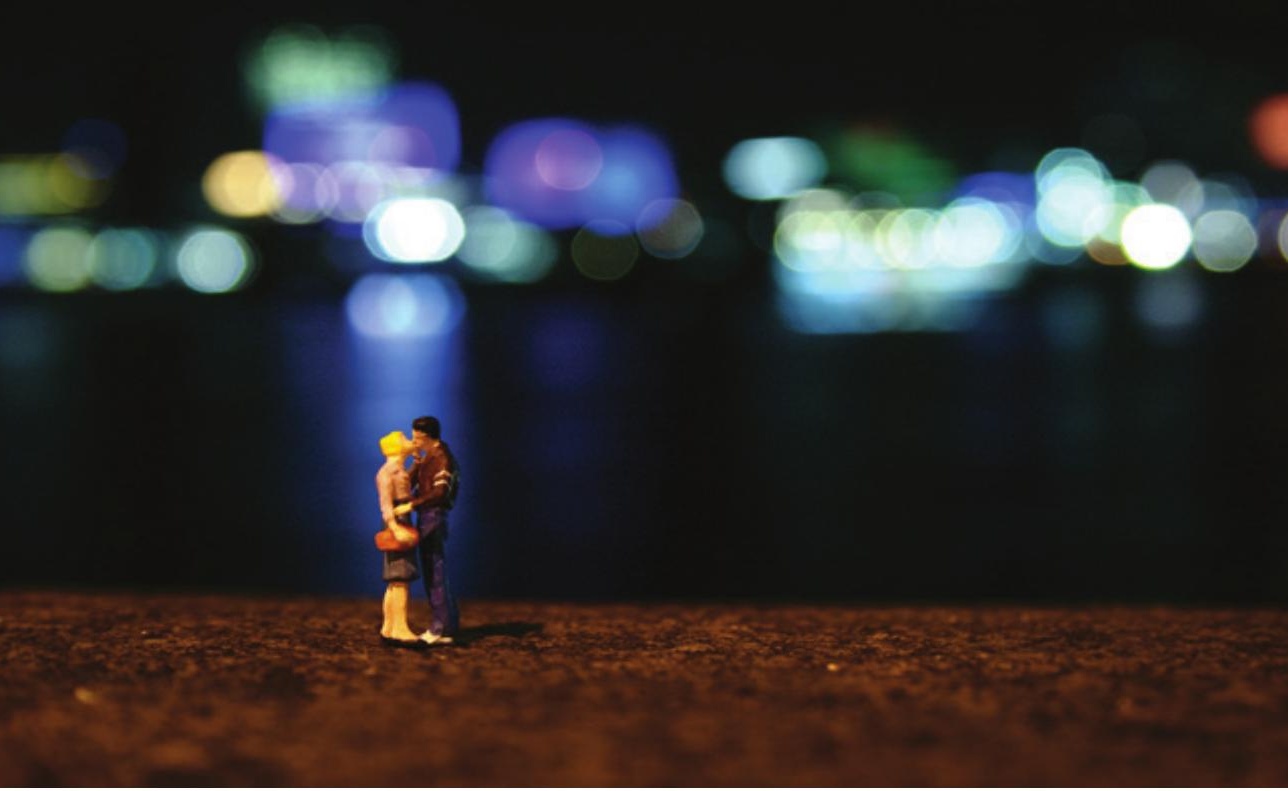

Na primeira imagem da série vemos uma cidade à noite, suas luzes e um provável rio. Nela, há um minúsculo ponto colorido, ligeiramente saliente, sobre um comprido muro. É quase impossível notá-lo, pois é o amplo contexto ambiental da fotografia que grita, que impõe seus sentidos. Na segunda imagem, vemos, em primeiro plano e em super-close, esse pequeno ponto da imagem anterior. Eis que surgem diante de nós as pequenas pessoas-objetos da arte urbana de Slinkachu. O foco nelas (minúsculas e quase "invisíveis" na fotografia inicial) tira o contexto anterior de cena e nos incita a criar sentidos outros à primeira imagem da série. Ela jamais será a mesma! Estará, agora, aberta a narrativas (in)imagináveis. Em outras das suas séries, considero importante referir, 
somos instigados a ver a textura da cidade: seus rugosos chãos, suas reentrâncias, fissuras, desníveis, ao mesmo tempo em que testemunhamos nossa pequenez diante do urbano.

Tal como Slinkachu, colocaríamos o mesmo ponto colorido da série "Last kiss" no chão esfumaçado da nossa demasiadamente sustentada foto de capa. Ao lado da mesma disponibilizaríamos uma segunda fotografia produzida por um mega super-close no pequeno casal-objeto em seu último beijo. $\mathrm{O}$ escapamento-sujeito desapareceria e o caminhão-contexto seria, agora, apenas luz embaçada. Lembraríamos, até mesmo, quem sabe, da cena final de "Casablanca", filme de 1942, em preto e branco, dirigido por Michael Curtiz. Recordaríamos a ausência do último beijo (e a expressividade dos olhares apaixonados) de Ingrid Bergman e Humphrey Bogart na neblina esfumaçada de uma noite ligeiramente fria no pátio de um campo aeroviário.

E a série estaria composta pela nossa fotografia de capa (agora com um ponto colorido quase imperceptível no asfalto) e uma outra parecida com a segunda de "Last kiss". Nossa primeira foto (bem como a imagem de capa do Caderno jornalístico) jamais será a mesma! Criaríamos, quem sabe, nessa operação, uma imagem, de saída, (im)pensável e, quiçá, insustentável! 


\section{Ensaiar a escrita, exercitar o pensamento}

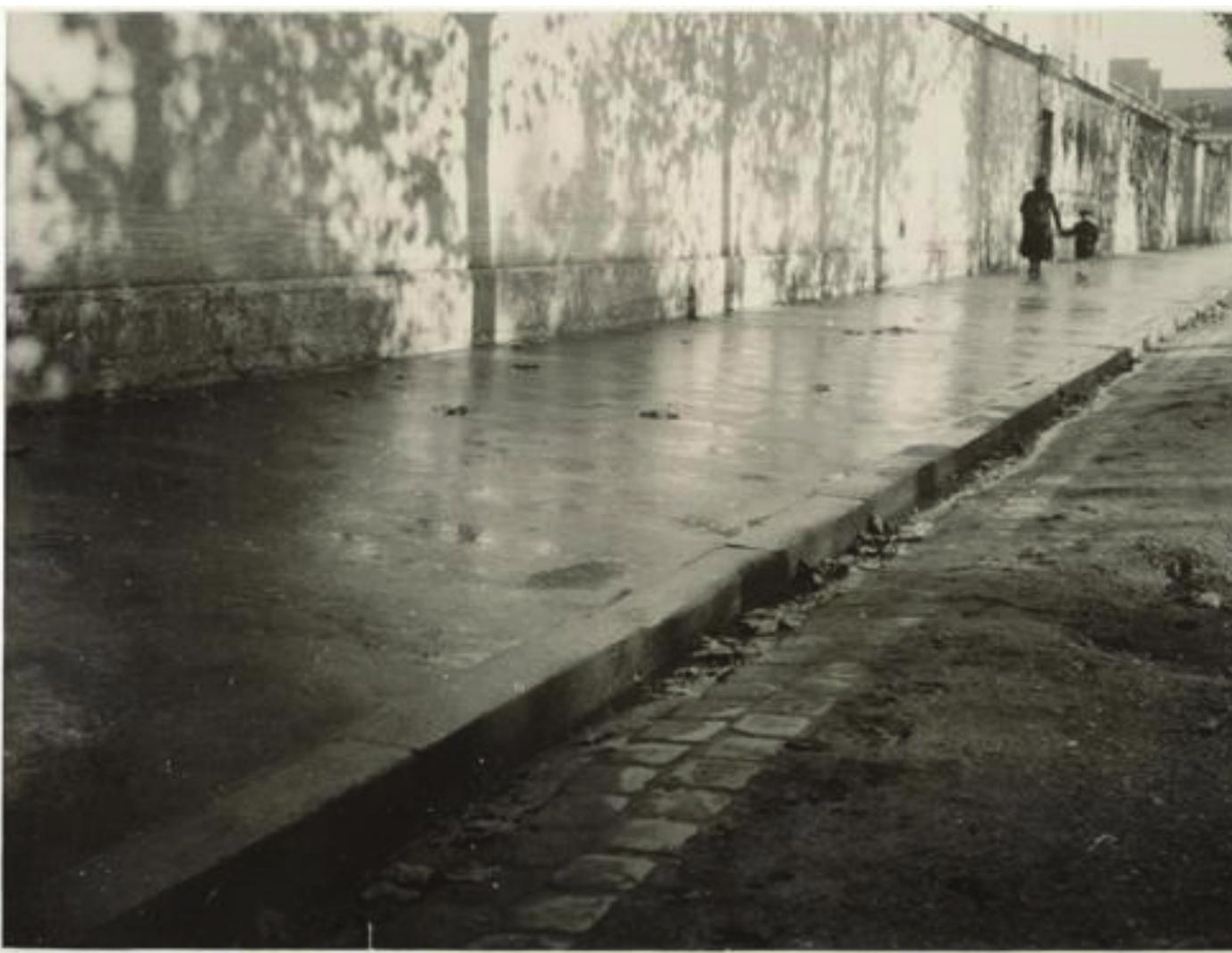

Com este ensaio pretendi criar um problema na relação da fotografia e sua legenda-título, em uma imagem de capa de um Caderno jornalístico focado em sustentabilidade. A questão que me tomou foi: como pensar a fotografia sem a clausura do dispositivo que a captura? A quase impossibilidade de pensar a imagem (e a foto) fora do "dispositivo da sustentabilidade" me atordoou. Cambaleando, procurei promover, nela, rasuras. Para isso, Michel 
Foucault (e Magritte) e Slinkachu foram imprescindíveis. Com tais exercícios, o desconserto pôde ir um pouco além da imagem e atingir o próprio dispositivo que a cerca, a empareda. $\mathrm{O}$ ensaio não o abalou, certamente, mas, sim, aquele que o assinou. E, para mim, isso já foi demasiado.

Tal como a foto que abre essa seção final, de Dora Maar ${ }^{6}$ (intitulada: "après la pluie"), um muro (ou muitos) parece estar, sempre, a nos estreitar os caminhos (sustentáveis?) que deveríamos seguir vida afora. Muro-dispositivo que se movimenta, pois, tal como a imagem da fotógrafa francesa nos sugere, o podemos enxergar diferente a cada percurso da luz solar, a cada posição do olhar, a cada lente acionada para vê-lo. E, com ele, caminhamos lenta e interminavelmente, como se quiséssemos chegar lá onde apenas o horizonte estará. Como o ensaio aventou, o muro de palavras que emparedou a fotografia não era necessário à imagem, pois o "dispositivo da sustentabilidade" já nela atuava de forma sutil e insinuante, independentemente do que estaria, naquela capa jornalística, escrito. Talvez, qualquer dispositivo nos force a ver, a selecionar lentes, a escolher imagens, a atuar sob o efeito de sua persuasão. Mas também, ao mesmo tempo, nos exercita o pensamento através do esforço do escape, da invenção de uma escrita ensaística, da composição de imagens outras, mesmo que, ainda, quase tudo seja costurado através das linhas do próprio dispositivo que desejamos exaurir.

E foi a sujeira e a subjetividade do ensaio (diferentemente do que chamamos de artigo científico - em que a limpeza e a objetividade imperam) que me permitiu, sem menos rigor (sobretudo

6 Vi a fotografia da artista na visita que fiz ao "Centre Pompidou", em Paris, na primeira semana de maio de 2013. A foto pode ser conferida diretamente no site do museu: http://bit.ly/12gPCof 
com os conceitos pós-estruturais operados no texto), ser infiel ao "dispositivo da sustentabilidade" - às suas sedutoras e envolventes linhas de poder-saber que estabilizam sentidos e criam verdades.

Josué de Castro (1965) nos disse (e nele me inspirei) que o ensaio é um texto não espartilhado na camisa de força de uma metodologia. Não é neutro, muito menos pretende alcançar uma fria análise científica do que chamaríamos "realidade social". O ensaísta, nos sugere um dos principais pensadores do Brasil profundo no século XX, não é um "simples inventariante de tudo aquilo que se apresenta aos seus olhos, teleguiados por métodos de trabalho consagrados" (CASTRO, 1965, p. 15). O ensaio de Josué de Castro é uma composição textual comprometida com o sonho. Texto tecido em viagem, atento aos movimentos incessantes da cultura e da vida cotidiana. Nele estão expostos (sem entrelinhas) os bastidores do seu pensamento. Ali desfilam suas referências científicas, literárias, poéticas, filosóficas, musicais. Um texto que acolhe e convida o leitor à viagem.

Não conseguiria escrever o que rascunhei sem também estar em viagem. Por vezes, propiciada pelos trens e aviões que me levaram a museus, ruas, livrarias, lojas de disco, parques, praças, mercados a céu aberto, cinemas, jardins, restaurantes, centros culturais, galerias de arte, cafés, bibliotecas, teatros, "pedaços" (MAGNANI, 1984) de cidades instigantes próximas à Amsterdã. Por vezes, a viagem foi também oportunizada por textos escritos (sobretudo literários) e/ou imagéticos, músicas, conversas, gestos vividos no cotidiano do lugar em que estava? ${ }^{7}$ Para este texto, parece tam-

7 Foi David Bowie (sobretudo os discos "Hunky Dory" e "Let's Dance") quem escutei de forma exaustiva, mesmo que intermitente, no tempo final de escrita deste ensaio. Também me acompanhou em todo processo o livro intitulado "Eles eram muitos cavalos" de Luiz Ruffato (2010), com sua escrita 
bém ter sido necessária certa dose de aventura na escrita. Apenas duvido que tenha conseguido "pensar de outro modo", tal como nos disse Jorge Larrosa (2003) desde a epígrafe que abriu o ensaio. Por vezes me senti dizendo mais do mesmo e isso me fez chegar até aqui um pouco ofegante, como se tivesse acabado de correr minha primeira maratona ${ }^{8}$. Acho que, agora, retornarei um pouco mais lento, para que a respiração encontre outro ritmo. Espero poder, em breve, começar a "ler de outro modo" para ver se consigo "escrever de outro modo".

\section{Referências}

CASTRO, Josué de. Sete palmos de terra e um caixão: ensaio sobre o nordeste, área explosiva. São Paulo: Brasiliense, 1965.

FOUCAULT, Michel. Sobre a história da sexualidade. In: FOUCAULT, Michel. Microfísica do poder. Introdução, organização e tradução Roberto Machado. 18. ed. Rio de Janeiro: Graal, 2003.

Paz e Terra, 1988.

. Isto não é um cachimbo. Tradução Jorge Coli. Rio de Janeiro:

GUIMARÃES, Leandro Belinaso. Notas sobre o dispositivo da sustentabilidade e a formação de sujeitos "verdes". In: SARAIVA, Karla; MARCELLO, Fabiana de Amorim (Orgs.). Estudos Culturais e Educação: desafios atuais. Canoas: Editora da ULBRA, 2012.

LARROSA, Jorge. O ensaio e a escrita acadêmica. Educação \& Realidade. Porto Alegre, v. 28, n. 2, p. 101-115, jul./dez., 2003.

MAGNANI, José Guilherme Cantor. Festa no pedaço: cultura popular e lazer na cidade. São Paulo: Brasiliense, 1984.

entorpecida, cotidiana, inventiva, deliciosa. Agradeço a Marcos Reigota a indicação do livro.

8 Este ensaio foi pensado inúmeras vezes no interior do silêncio dos meus treinos de corrida pelo Westerpark, em Amsterdã. 
MELVILLE, Herman. Bartleby, o escrivão - uma história de Wall Street. São Paulo: Cosac Naify, 2005.

RUFFATO, Luiz. Eles eram muitos cavalos. Rio de Janeiro: BestBolso, 2010.

SAMPAIO, Shaula Maíra Vicentini de; GUIMARÃES, Leandro Belinaso. O dispositivo da sustentabilidade: pedagogias no contemporâneo. Perspectiva. Florianópolis, v. 30, n. 2, p. 395-409, maio/ago., 2012.

SLINKACHU. Little people in the city: the street art of Slinkachu. London: Boxtree, 2008. 